Review

\title{
Behavioral outcome measures to improve experimental stroke research
}

Mustafa G. Balkayaa , Rebecca C. Trueman ${ }^{b}$, Johannes Boltzec ${ }^{c}$ Dale Corbett ${ }^{d}$, Jukka Jolkkonen ${ }^{f^{*}}$

aBurke Research institute, Weill Cornell Medical College, New York, USA

bSchool of Life Sciences, University of Nottingham, Nottingham, UK

'Department of Translational Medicine and Cell Technology, Fraunhofer Research Institution for Marine Biotechnology and Cell Technology (EMB) and Institute for Medical and Marine Biotechnology, University of Lübeck, Lübeck, GERMANY

dDepartment of Cellular \& Molecular Medicine and Canadian Partnership for Stroke Recovery, University of Ottawa, Ottawa, ON, CANADA

fInstitute of Clinical Medicine-Neurology, University of Eastern Finland, 70210 Kuopio, FINLAND and Neurology, Neurocenter, University Hospital of Kuopio, 70210 Kuopio, FINLAND

${ }^{*}$ Corresponding Author: Institute of Clinical Medicine-Neurology, University of Eastern Finland, 70210 Kuopio, FINLAND. E-mail address: jukka.jolkkonen@uef.fi (J. Jolkkonen). 


\section{HIGHLIGHTS}

- Behavioral testing is indispensable for deepening our understanding of brain plasticity and in developing restorative therapies for stroke.

- Here we review the most common behavioral tests used to assess sensorimotor impairment and recovery, cognition and mood in stroke animals.

- Guidance is provided to help select the most appropriate behavioral tests as a way to further improve reliability and translational success of experimental studies.

\section{ABSTRACT}

Functional recovery after an experimental stroke can be assessed by multiple behavioral tests, however, there is no consensus about which test to use in long-term stroke recovery studies or whether the tests are affected by stroke surgery, post-operative care or behavioral compensation due to repeated testing. This review describes the tests most commonly used to assess motor and sensorimotor function, cognition and mood in stroke animals. Although it is difficult to predict the direction of future research, it may be possible to prevent false-positive results by selecting an appropriate task or a battery of tasks. It is also expected that the upcoming stroke recovery recommendations and the improved dialogue between academy, industry and healthcare professionals will further promote translational success.

Keywords: Stroke, Animal models, Behavioral tests, Sensorimotor function, Cognition, Depression, Anxiety, Restoration 


\section{Contents}

1. Introduction

2. Experimental stroke models and behavior

3. Most frequently used behavioral tests in rodent stroke recovery studies

3.1. Neurological scores and limb placing tests

3.2. Rotational asymmetries

3.3. Sensory impairments

3.4. Sensorimotor testing

3.5. Skilled forelimb use

3.6. Hindlimb functions

3.7. Gait analysis in rodent models of stroke

3.8. Kinematic analysis of behavior

3.9. Post-stroke cognition

3.10. Post-stroke neuropsychiatric disturbances

4. A comprehensive behavioral test battery to assess stroke recovery and treatment effects

4.1. Sensorimotor testing

4.2. Cognition

4.3. Mood

5. Large animals in stroke recovery research

6. Multi-center preclinical animal studies to improve translation

7. Toward better stroke recovery studies

8. Conclusion

References 


\section{Introduction}

Stroke is a leading cause of adult disability. Depending on the location and the extent of the lesion, $80 \%$ of patients suffer from motor impairments that typically affect the control of movement of the face, arm and leg on one side of the body [1]. Altered gait patterns, balance impairments, reduced muscle tone or power as well as reduced joint stability and mobility are commonly observed in stroke survivors. In addition, approximately every second stroke survivor suffers from sensory deficits [2,3]. Despite considerable heterogeneity, most patients exhibit some degree of spontaneous recovery in the weeks to months after a stroke [4]. For example, hemiplegic patients begin to execute voluntary movements within 6 to 33 days [5]. Within six months after the stroke, upper extremity dexterity is regained in $41 \%$ of people with moderate to severe stroke and in $78 \%$ with milder stroke [6].

It is becoming increasingly clear that cognitive impairment is also a significant concern for stroke survivors. In fact, there are reports that as many as $25-35 \%$ of stroke patients will develop dementia [7,8], and conversely many patients diagnosed with clinical dementia have been found to have a history of cerebrovascular pathology [9]. In addition, cerebrovascular lesions lead to numerous mood and emotional disturbances including depression and anxiety [10-12]. Post-stroke depression (PSD) is the most frequent and debilitating mood disorder encountered in stroke survivors which not only affects the patient's quality of life but also drastically increases hospitalization time, hampers recovery and rehabilitation efforts and increases mortality. The reported PSD prevalence rates widely vary, the mean prevalence rate for both major and minor depression is approximately $24 \%$ after a stroke in outpatient settings [13]. Anxiety occurs in roughly $30 \%$ of patients and it displays high co-morbidity with PSD [14].

Emerging knowledge about brain plasticity and endogenous repair mechanisms gives rise to hope that it may be possible to develop restorative therapies for stroke patients [15-18]. Experimental models are indispensable in this process $[19,20]$ and although the same models can be used in acute stroke research and long-term recovery studies, the major difference in long term studies is behavioral testing to assess functional outcome in recovering stroke 
animals. The aim of this review is to summarize the current repertoire of stroke outcome measures in experimental animals including sensorimotor functions, cognition and mood with guidance for future stroke recovery research and development of restorative therapies. Many of the tests can be used in either rats or mice and in this review these species will not be separated unless a major species difference exists. Recommendations for behavioral testing in large animals, excluding non-human primates, are also discussed.

\section{Experimental stroke models and behavior}

A number of stroke models have been described for rodents [21]. Rodents are often the first choice due to the fact that rats and mice possess a vasculature similar to humans, a rich behavioral repertoire along with a number of well described behavioral outcome measures that assess similar limb movements as used by humans. Recovery mechanisms can be further explored in transgenic mice, allowing the role of specific proteins or pathways to be studied. One major factor confounding reliable modeling is the variation in inter-subject vascular anatomy leading to differences in the locations and size of the infarct [22]. Another concern is the invasive nature of stroke induction, which requires anesthesia and post-operative care. Anesthetics may exert mild neuroprotective effects that can slow the maturation of the infarct. It is still unclear whether or not this influences the animal's long-term recovery. Some common anesthetics have their own distinctive properties, e.g., isoflurane opens the blood-brain barrier, which is already affected by ischemia [23]. Isoflurane may also induce preconditioning [24]; this can be a problem in follow-up studies involving repeated procedures such as imaging. Less attention has been paid to the optimal post-operative care and analgesics [25]; these drugs may also exert an effect on maturation of damage and brain repair mechanisms. Severe weight [26] and vision loss [27] which are present in some stroke models (e.g., the intraluminal suture model) can impact on the animal's performance in behavioral tests. Side effects such as cauterization of the external carotid artery, also affect behavioral performance independently of the ischemic brain lesion [28]. Given these complications, it is unfortunate that there has been limited development of new stroke models or efforts to improve the existing methods. 
There is also a need for less invasive techniques to produce brain ischemia that could reduce exposure to anesthetic agents and analgesics.

Alongside issues inducing ischemic damage, other factors also affect behavioral

outcome. Proper handling, pretraining and housing conditions have a major impact on outcomes. For example, single housing, social housing or enriched environment can alter behavior and recovery from stroke [29]. In efforts to mimic clinical rehabilitation, evaluation of restorative treatments should be assessed with and without environmental enrichment or training. Less attention has been paid to the fact that rodents are nocturnal animals but they are often tested and treated during the lights-on period when they are less active, although a reversed light-dark cycle is easy to implement.

In addition to these external factors that can influence behavioral outcomes, rodents show substantial recovery after a stroke. After a focal stroke, mice rapidly recover within 2 to 3 weeks, rats within 3-4 weeks. In terms of observable sensorimotor deficits, they become indistinguishable from naive animals unless sensitive tests are employed [30,31]. One challenge is to detect impairments in experimental stroke animals since in the wild, animals are forced to hide deficits and illnesses to ensure their survival. In addition, rodents often develop compensatory strategies to complete a given task, leading to erroneous conclusions about the extent of recovery. Indeed most behavioral tests only assess performance, little attention is paid to the way the animals complete the task. The validity of behavioral tests to differentiate compensation from true functional recovery has been recently discussed [32].

Behavioral tests to evaluate functional impairment during recovery are numerous [30,31,33-36]. Task selection is often based on the time needed to conduct each test and on the fact, that special expertise or devices are not required. In the next sections, we will review the most common tests used to assess motor and sensorimotor function, cognition and mood in stroke animals.

\section{Most frequently used behavioral tests in rodent stroke recovery studies}


Stroke recovery studies rely heavily on behavioral testing. A number of tests for assessing sensorimotor function, cognition and mood are available to detect acute and longlasting deficits (Figure 1, Table 1).

\subsection{Neurological scores and limb placing tests}

Modified neurological severity scores (mNSS) measure reflexes to various stimuli, balance and simple motor functions giving a total score for gross behavioral impairment [37]. Their advantage is that the animals can be tested immediately after the surgical procedure, but subjective scoring may give false positive results and summing up scores from different subtests may obscure significant results. Since there is a spontaneous recovery within a week or two, mNSS tends not to be useful for long-term studies [36,38]. For example, a recent systemic review on the elevated body swing test, a procedure usually included in mNSS, showed inconsistent swing profiles in ischemic rats, and furthermore, these tended to shift over time [39]. This observation suggests that caution should be exercised in selecting simple behavioral tasks for stroke recovery studies.

The limb-placing test is another simple task, which assesses the sensorimotor integration of fore- and hindlimb responses to tactile and proprioceptive stimulation [40]. The test has several limb placing tasks, which are scored as follows: 2 points, normal response; 1 point, delayed (>2 s) and/or incompletely response; and 0 point, no response. Depending on lesion size and location, the deficit can be long-lasting [41]. Forelimb placing can also be triggered by the stimulating a rat's vibrissae or holding a rat at $45^{\circ}$ above a bench, with one forepaw restrained and slowly dragging the other forepaw sideways across the bench [42].

In mice, the SHIRPA battery is a standardized tool for behavioral phenotyping and screening of motor impairment [43].

\subsection{Rotational asymmetries}

Unilateral focal ischemia of the middle cerebral artery (MCA) territory induces prominent ipsilateral circling behavior in rodents, which subsides within a few days. However,

evidence from the rotational asymmetry test suggests that the hemispheric imbalance is not 
compensated completely and a profound turning preference persists in the experimental animals for months with very minor spontaneous recovery [30,31].

The bowl test is a simple task for evaluating rotation in rodents. In the classic set-up, animals are placed into a glass or Plexiglas bowl connected to a special harness with a tether attached to an automated rotameter. Clockwise and counter-clockwise rotations are recorded to measure the rotational asymmetry during the test period, usually lasting 30 to 40 minutes [44]. Alternatively, a laterality index can be calculated by dividing the difference between the number of clockwise and counter-clockwise rotations with reference to the total number of rotations [30]. One drawback of the setup is the harness used to attach the animals to the tether which can be cumbersome and stress-inducing for the animals. With the availability of novel video tracking systems, it has become possible to reliably measure rotation from video analysis without the need for a mechanical rotameter or constraining harness. The amphetamine/apomorphine induced rotation test has been used in a limited number of stroke studies [30,45-48]. Rotational asymmetry after striatal strokes is apparently a robust and replicable phenotype. In animals with larger infarcts, there is no need for pharmacological manipulations.

\subsection{Sensory impairments}

Impairments in tactile sensation, which are present in at least $50 \%$ of stroke survivors, are more common than proprioceptive deficits and more pronounced in individuals with cortical lesions compared to those with subcortical strokes [2]. Behavioral tests evaluating tactile performance would be ideal to study recovery since adaptive behavior to compensate for a lost sensation is rather unlikely [49].

The adhesive removal test is a sensitive test for evaluating sensory and motor impairments after unilateral lesions involving the sensory-motor cortex, the corticospinal tract, and the striatum [31]. During the test, small adhesive tape patches are applied to one or both paws depending on the protocol. The animal is then released to its home or a test cage. Naïve

animals rapidly sense the alien object and react to it quickly. The latency to contact and remove the patch is recorded, typically with a cutoff time of 120 seconds [50]. Contact refers to any sort 
of behavior indicating that the animal is aware of the patch such as paw shaking or touching it with its mouth. In protocols where both paws receive a patch, animals with unilateral strokes tend to touch and remove first the patch on the ipsilateral forelimb. The order of contact and the latency to contact on the contralateral paw are indicators of the sensory deficit, while an increase in the removal time is a result of both sensory impairment and motor learning. Detection of long term deficits has been reported in some studies using stroke models but not in others [51]. This is likely related to the degree of the brain damage [36].

\subsection{Sensorimotor testing}

Rotarod is one of the most commonly used assessments of sensorimotor coordination and balance in stroke rats and mice [52-54]. This test is easy to perform, i.e. one measures the time that the animal can remain balanced on a rotating rod as the device accelerates. One major disadvantage of the test is that it cannot discriminate spontaneous recovery from therapy induced recovery, the former being partly due to postural adjustments that subjects

develop during repeated testing. Nevertheless, long term deficits have been reported following ischemic damage, but this can be dependent on the strain of rat in use [55].

Another frequently used test is the cylinder test, which is based on the rodent's own exploratory activity in a transparent Plexiglas cylinder [42]. When the animal is placed in the cylinder, it initiates vertical, exploratory scanning of the wall by touching equally with its left and right forelimbs. After brain ischemia, there is a reduction in use of the impaired forelimb in first wall contact and a significant reliance on non-impaired forelimbs [56]. One disadvantage of this test is that too frequent testing results in rapid habituation with less tendency to rear and explore the cylinder.

The corner test is also used to evaluate persistent asymmetries in turning preference after focal ischemia. In the classic version, animals are introduced to a testing apparatus consisting of two connected cardboard walls forming a $30^{\circ}$ angle. At the junction of the walls a small opening is cut to motivate animals to enter deep into the corner. Typically, animals move towards the small opening at the junction and after a brief exploration they rear and make a 
turn to one side. Mice develop a clear preference towards the lesion (ipsilateral) side after a focal stroke which has damaged the striatum [30,31]. Similarly, in unilateral embolic middle cerebral artery occlusion (MCAo), the corner test has been claimed to be very sensitive in distinguishing sham from stroke animals up to 90 days post-stroke [57]. Numerous other studies employed the corner test for long term assessments in various focal stroke models $[50,58,59]$. Interestingly, the corner test was either unable to reveal any difference between groups in distal MCAo or cortical infarct models where the striatum had been spared $[60,61]$ or at best, they displayed a mild transient contralateral preference [62].

\subsection{Skilled forelimb use}

Montoya's staircase test is frequently used for rats [63]. In this test, mildly foodrestricted animals are trained to pick up foot pellets from a set of stairs on either side of a raised central platform that supports the animal's body. The test box is designed so that the animal can use only the right forelimb to grasp the pellets from the right side and vice versa. The typical training period lasts 2-3 weeks in rats. Post-stroke testing is done in a similar fashion at intervals usually beginning no sooner than 5-7 days' post-stroke $[64,65]$. The impairment is long-lasting or permanent and the performance is not affected by repeated testing. The test is more challenging for mice and therefore the single pellet task is preferred for this species.

A more comprehensive assessment of reaching behavior can be achieved using the single-tray reaching task in conjunction with kinematic analysis [66-68]. The reaching boxes are often custom-made from Plexiglas with a slot in the middle of the front wall to force the animal to reach for food pellets that are placed on a shelf attached to the outside of the front wall in two small indentations. Rats are individually habituated to the reaching boxes and trained to reach for food pellets [69]. The pellets are placed contralaterally to their preferred paw. Training lasts about 4 weeks until the success rate in individual rats no longer increases. A successful reach (quantitative analysis) is defined as a reach that allows the rat to grasp the food pellet and consume it. Reaching accuracy is scored as the percentage of successful reaches per total number of pellets available in each session. If high speed video capture is 
used and the movements that make up the reach are individually scored, then the test can be used to differentiate true motor recovery from compensatory movement strategies [70,71].

Another simple and quantitative way to study paw and digit function is the pasta handling test $[60,72]$. The major difference compared to reaching tasks is that pasta handling is a bimanual task. Slow-motion video analysis allows quantification of detailed fine digit and bimanual movement patterns as the pasta is eaten. Focal cerebral ischemia does not increase eating time, but leads to a prolonged reduction due to adjustments being made with the contralateral forelimb. In addition, ischemia increases atypical behaviors. Minimal training, repeated and long-term testing within a few minutes are the key advantages of the pasta handling test.

\subsection{Hindlimb functions}

Not many tests exist for testing hindlimb function, but the tapered/ledged beam and grid walk tasks are recommended. In the tapered/ledged beam test, the animal has to walk along a gradually narrowing beam to reach its home cage or a darkened goal box [42]. The ledge on either side of the beam enables the rats to correct their balance should their foot slip from the beam, especially as the beam becomes narrower. In some models, the impairment seems to be permanent [73]. Grid walking (foot-fault test) and the ladder task are other tests which have been used to assess hindlimb impairment after a stroke $[38,74,75]$.

\subsection{Gait analysis in rodent models of stroke}

In humans, a wide range of sensorimotor problems including decreased motor control, problems in dexterity and accuracy, muscle weakness, spasticity and proprioceptive impairments interfere with normal gait [76], causing walking dysfunction [77]. Thanks to recent advances in behavioral testing technologies, advanced gait analysis has become a viable, valuable and affordable tool in preclinical research.

Prior to the introduction of computer assisted systems, a rather basic gait analysis was possible by applying ink to the paws of the animal and allowing the animal to walk over paper. The footprint dimensions (length, width) and distances between prints were measured to 
determine stride length, hind paw drag [78] and degree of asymmetry. Computer assisted gait analysis systems (CAGAS) rely on detecting footprints from video recordings of the moving animal registered from underneath a transparent walkway. From the paw print patterns, each paw can be discriminated and parameters such as the length and width of the paws, amount of pressure exerted on each paw and the duration for which each paw stays on the surface can be calculated. By using these basic parameters and their temporal relations, a large array of numerical data about the kinematics of ambulation and gait can be acquired, allowing the revelation of slight impairments. A detailed description of available gait parameters can be found elsewhere [79].

CAGAS are increasingly used in preclinical stroke research and seem to offer impressive long term sensitivity. In proximal MCAo models, numerous gait analysis parameters were significantly different among groups at the acute [31,38,80-82] and late time points $[31,38,82,83]$ both in rat and mouse studies. In distal MCAo models, where impairments are less severe and harder to detect, CAGAS nonetheless revealed significant alterations [62] and this approach has also been exploited to examine the effects of therapeutic interventions [84].

Despite the impressive technology and in-depth analysis possibilities offered by CAGAS, there are also major shortcomings inherent in the widely used setups. In a proximal MCAo model in mice, of the total of 100+ parameters, 66 correlated with average speed; 14 of these were significant for group differences [30]. An apparent solution to this problem is using CAGAS systems that can operate on a treadmill with a fixed speed. In the same study, stroke-induced weight loss affected several parameters in the acute phase although the correlations tended to diminish as the animals gained weight. In rats, however, weight differences and loss seem to represent an even greater problem. In a $60 \mathrm{~min}$ transient MCAo model, Parkkinen et al. reported a significant correlation between body weight and some major parameters such as swing speed, maximum paw contact area, paw print area, paw print width, and toe spread [85]. This suggests that intensity-related parameters should probably be totally excluded in rats. Taken together, parameters related to relative position between the paws and inter-limb coordination appear to be less susceptible to weight and speed bias. 
In summary, CAGAS offers impressive insights into gait alterations after stroke and represents a valuable tool for distinguishing recovery from compensation. Nonetheless, investigators should be aware of the limitations of their setup and employ vigorous training schedules along with very stringent criteria to denote "successful" runs.

\subsection{Kinematic analysis of behavior}

Kinematic analysis of human motion has a long history and important applications ranging from basic research to clinical evaluation. Kinematic data has proven particularly valuable in the rehabilitation field for discriminating between healthy and pathological conditions, deciding on appropriate rehabilitative treatment and assessing its efficacy [86]. In stroke rehabilitation, kinematic measures of upper extremity movements [86], movements of head, trunk, pelvis [87], and locomotion [88] are gaining wider applications. Reaching ability is

often severely impaired in stroke survivors, making kinematic analysis of reaching tasks a particularly interesting focus in post-stoke rehabilitation research $[89,90]$.

It is possible to analyze the kinematics of rodent behavior. Detailed analyses of mouse and rat locomotion have been described in the literature [91-93]. In a few studies, the effects of various external conditions and biological variables ranging from age to hypergravity have also been analyzed $[94,95]$. In malonate-induced lesions of the dorsal striatum, 3D motion capture technology was used to assess treadmill running kinematics in rats with and without obstacles. Lesioned animals contralesional limbs exhibited changes in length and timing parameters, and were found to be overflexed [96]. Eftaxiopoulou et al. described compensatory behavior in adjusting the gait in a model of temporal nerve palsy using 3D angular kinematic analysis of treadmill locomotion. An increase in the overall range of motion of the hip and an increase in the initial ankle angle during the swing phase were observed in those animals exhibiting compensation [97].

A limited number of studies have used kinematic approaches in stroke research. Braun et al. employed kinematic analysis in a classical skilled reaching task [98]. As the rats were reaching for a food pellet through a narrow slit, their paw movements were tracked and plotted in a 2D plane, giving a trajectory for each attempt. This study demonstrated significant 
differences in reaching trajectories between control stroke and bone marrow cell treated stroke animals. Over the course of 10 weeks, both groups showed improved performance, however, the non-treated stroke animals did so via compensation, involving increased trajectory adjustments. Another study used the same approach in a mouse photo-thrombotic focal ischemia model and reached similar conclusions [99].

As mentioned above, kinematic studies do not necessarily need to use sophisticated equipment and software combined with complex angle and motion analyses. Describing a typical behavior during a task by defining the components and sequence along with anatomical description of joint rotations already allows for a detailed quantitative scoring. By adapting previous studies, Knieling et al. devised a skilled reaching test to evaluate recovery and compensation in a photothrombosis model of stroke [69]. A skilled reaching task that typically relies on the number of successful reaches was videotaped and analyzed after breaking down the typical reaching movement into three separate components (reaching, grasp, withdrawal) which were further divided into 35 subcategories. Each category was scored for its adherence to normal pattern. This demonstrated effective compensation in experimental stroke animals and that this could be facilitated by provision of an enriched environment. Another study used a similar approach with a simpler gesture analysis method and observed "learned bad use" with excessive gestures in the stroke rats [100].

\subsection{Post-stroke cognition}

The Morris water-maze is undoubtedly one of the most widely used behavioral tasks in neuroscience [101]. A number of variations exist, but the general concept is to train the animals to locate an underwater hidden platform based on spatial cues placed around the pool. Learning is assessed by giving the animal 4-5 trials with a short rest between trials. A typical training period takes 3-4 days. If the animal fails to find the hidden platform within a fixed time, it is placed on the platform by the investigator. The starting point is changed after each trial. The swim paths are monitored by a video camera connected to a tracking program. Escape latency (time to reach the platform), time spent in each quadrant of the pool and swim path length are used to assess water-maze acquisition. Swim speed is used to assess motor 
capabilities while a visible platform can assess altered visual acuity since both may confound the memory analyses. Usually a probe trial is performed after the last training run by taking the platform away to control how well the animals remember the position of the platform. In MCAo rodents, the impairment of water-maze navigation is long-lasting [102]. However, thigmotaxis behavior (e.g., swimming in the outermost annulus of the pool) is observed [103], indicating that sensory deficits contribute to the result. To overcome possible misinterpretation, training to a predetermined performance criterion has been proposed [104]. The water-maze performance of mice is significantly inferior to the performance in rats [105]. Hypothermia may also confound the test results in mice [106].

The radial arm maze is another frequently used method to study learning behavior and memory impairments. The apparatus consists of a central platform with a variable number of arms, from 4 to 8 (standard) up to as many as 17 [107]. Two main procedures have been described: 1) working memory and 2) working memory/reference memory version. In the first version, the animal is allowed to explore and obtain food reward. A computer records which arms the animal visits once versus those that are revisited (errors). The second version is the combined working/spatial memory in which some arms are baited in each trial and some are not. Revisits to baited arms are scored as working memory errors and entries into never-baited arms are scored as reference or trial-dependent errors. Similar to the water-maze, this task may be confounded by sensorimotor deficits, so care has to be taken when applying this task in stroke models.

There is rather limited experience with other cognitive tests in stroke animals and with considerable differences in results. There are a few publications describing auditory fear-conditioning [108,109], [108,109], object recognition tests models [110], and passive avoidance test [50,111,112]. It has been claimed that delayed performance in passive avoidance test correlates with cortical and striatal damage [50].

\subsection{Post-stroke neuropsychiatric disturbances}

Studying depression and anxiety-like behavior in rodent models has a long history in behavioral phenotyping and antidepressant drug screening [113,114]. Behavioral despair induced by stressful and aversive conditions can be tested with simple paradigms such as the 
forced swim test [115] and tail suspension test [116], but in models of stroke, the motor impairment may confound these tasks. It is hard to deduce if "giving up" on these tasks is truly a reflection of depression or increased fatigue due to the motor effects of the stroke. Reductions or loss of capacity to experience pleasure, namely anhedonia can also be evaluated via sucrose consumption/preference tests $[117,118]$. An evaluation of anxiety-like behavior is possible with the light-dark box, elevated plus maze and novelty-induced hypophagia tests [113]. Modeling of post-stroke depression and other mood disorders in the context of stroke is a relatively recent endeavor and behavioral findings, especially from focal ischemia models, have been inconsistent between different laboratories.

In a unilateral medial prefrontal stroke model, Vahid-Ansari et al. showed a robust PSD phenotype in mice [119]. While this model is certainly of interest, the fact that frontal strokes are rare in humans limits its translational value. Ischemia-associated increased activity (right MCAo) and anxiety (left MCAo), but no post-stroke depression, was reported in animals tested eight weeks' post-stroke [120]. Another report by the same group described anxiety, anhedonia and depressive-like behavior in animals with stroke when tested at a later time point $(\sim 13$ weeks) [121]. Using sucrose consumption test, Craft and DeVries observed a hedonic deficit two weeks' post stroke in animals with right MCAo [122]. Similarly, Kim et al. showed that left MCAo animals displayed behavioral despair in the forced swim test (FST), especially between weeks 3 to 5 post-stroke but there was no effect on sucrose consumption [123]. The same study investigated the effects of chronic mild stress (CMS) after the stroke. A synergistic effect between MCAo and CMS was observed, intensifying stroke-induced mood disturbances. Interpretation of experimental results is further complicated by findings showing that behavioral phenotypes evolve with time and depend on housing conditions. In the study of O'Keefe et al., right MCAo mice were less immobile in FST at week two and only displayed behavioral despair (increased immobility) when housed in isolation [124]. When tested at day 33 post-stroke, right MCAo animals were significantly immobile for longer times compared to control mice and furthermore, the housing condition exerted no synergistic effect. Similar conflicting findings have also emerged from rat studies [125,126]. 
Numerous research groups have adopted the strategy to expose experimental stroke animals to varying durations of CMS or isolation which apparently produce more robust and reproducible PSD-like behavior $[124,127,128]$. However, it has to be kept in mind that CMS and social isolation procedures are already used in animal models inducing anxiety, and anhedonia in the absence of cerebral damage $[118,129,130]$. Therefore such approaches may not be optimal models of PSD unless a clear and substantial synergistic effect (as opposed to the additive effect detected in most studies) is observed.

Stroke is an age-related disease occurring with much greater prevalence in the elderly. Compared to young animals, aged rodents differ in their physiological response to experimental stroke. Older animals develop larger infarcts, blunted behavioral recovery, and exhibit a distinctive gene expression profile [131]. It has been reported that aged rats develop consistent PSD-like phenotype whereas young rats recover fairly well after MCAo [132,133]. This important finding, however, awaits replication by other groups.

\section{A comprehensive behavioral test battery to assess stroke recovery and treatment effects}

\subsection{Sensorimotor testing}

Currently there is no clear consensus about which tests should be used in assessing sensorimotor functions after stroke. The advantage of neurological severity scores and limbplacing tests is their simplicity. These tests can be used during the acute phase to exclude animals with an incomplete lesion or for the allocation of animals to equivalent groups with respect to impairment. However, the impairments resolve so quickly that they have limited utility in stroke recovery studies. If one wishes to detect long-term deficits in models with striatal and cortical damage, Montoya's staircase, single-pellet reaching, foot-fault, cylinder and adhesive tape tests are potential options, in that order of preference. They require training, and in some cases, time-consuming data analysis, but most importantly, they are better approximations of the chronic impairments that characterize human stroke. However, the 
model used and the extent of ischemic damage need to be considered, as some tests are only sensitive to deficits in models with more extensive brain damage.

In order to differentiate compensation from true recovery, reaching tasks with video recording and movement analysis are the best option. This approach can reveal specific movement patterns including extension, aiming, and grasping, which can be scored. The reaching tasks, particularly during training part, are laborious limiting their large scale use but the recently described automated behavioral boxes may be helpful in this respect $[134,135]$. In these systems, not only training is automated, but duration and difficulty can be controlled, and performance analyzed during reaching behavior in near real-time by MATLAB-based software [134]. It is noteworthy that other tasks such as treadmill, Rotarod, pasta handling and ladder rung can gain significant sensitivity when subjected to kinematic analyses.

In conclusion, multiple behavioral tests are able to detect long-term sensorimotor impairment and differentiate recovery from compensation when combined with kinematic analysis, thereby offering valuable tools for monitoring stroke recovery. However, this will increase workload, costs, and it inevitably results in more complex study designs. Nevertheless, such changes are necessary in order to increase the translational value of preclinical stroke recovery research. At the same time, automated training devices allowing high throughput testing are becoming more sophisticated and more widely available. For example, Intellicage and PhenoWorld type automated test environments may provide unique data about daily activities in a normal social environment and reveal stroke-related impairments otherwise missed by conventional tests. Ultimately, quality and reliability of data should not be sacrificed for expediency.

\subsection{Cognition}

Post-stroke cognitive impairment is a clinically important problem, but has received less attention in both clinical and preclinical stroke research. Most preclinical studies have used the Morris water-maze, which is a measure of hippocampal function. This test is also affected by coexisting sensory and motor deficits, possibly confounding the data interpretation. A greater concern is that hippocampal injury is rare in human stroke and thus the validity of the water 
maze to assess post-stroke cognitive functions is highly questionable. Another issue is that rodent cognition is far less lateralized than in humans and this may require the use of bilateral injury models to create deficits in higher order executive functions such as attention set shifting [136]. Clearly, learning and memory tests have been less validated for stroke animals and this is an area that could be enhanced by exploitation of automated touch-screen cognitive testing systems [137].

\subsection{Mood}

Despite the prevalence of post-stroke depression, its pathophysiology has been grossly overlooked. The numbers of clinical studies are limited and animal models require much greater refinement and validation. As such, a review of the literature suggests that MCAo in aged rodents may offer sufficient construct validity [131].

\section{Large animals in stroke recovery research}

Large animal models may have some advantages over rodent models since large animal species mostly possess a gyrencephalic brain, and furthermore their physiological functions and the grey-to-white-matter-ratio better approximate to those of humans [138]. Another significant advantage is their suitability for combination with imaging technologies [139], the opportunity for long-term surveillance and the possibility to gain more information from a single experiment/subject than can be obtained in rodent models (e.g., more complex and parallel physiological monitoring and readout). Several methods for behavioral phenotyping have been described. These range from simple scoring scales [140] to more sophisticated gait analysis systems [141]. Test batteries for cognitive function are also available since cognitive decline during ageing is a common phenomenon in domestic pets [142]. However, large animal stroke research is laborious, with expensive maintenance and it requires dedicated facilities with species-appropriate housing and care. Sample sizes usually tend to be smaller in large animal studies, but inter-subject variability is typically higher than in rodent models and therefore more comparable to that observed human clinical trials. The resulting reduction of statistical power requires careful design and selection of the primary endpoints to reach 
reliable statistical significance. For instance, advanced functional readout parameters [20] could be addressed together with strong and robust imaging endpoints. Thus, large animal stroke models are recommended to be primarily employed in confirmative rather than exploratory stroke research [143].

\section{Multi-center preclinical animal studies to improve translation}

In recent years, there has been a movement towards the delivery of experimental studies in the same fashion as phase III randomized control clinical trials [144,145] with multiple centers testing large numbers of animals, using standardized protocols and featuring central randomization, blinding and data analysis [146,147]. The Multi-PART consortium (Multicentre Preclinical Animal Research Team; www.multi-part.org) has developed a framework for the design and conduct of this type of preclinical trial. The aim of this is not to replace basic exploratory research, but to take therapeutic targets which have shown promise and test them in a robust fashion prior to clinical trials [143]. The motivation derives from a lack of translation from experimental studies, not only in stroke neuroprotection [148] but in many other disorders $[149,150]$. Systematic analysis of preclinical data has revealed several problems, e.g., poor experimental design, underpowered studies and lack of generalizability to other situations (models, gender, co-morbidities) [151-153] and these can be addressed by adopting a multicenter trial design. The aim of this approach is to improve internal validity (for example by using centralized randomization), and by introducing systemic variation, for example by exploiting different models, to increase external validity and the generalizability of results.

When designing such trials, it is paramount to consider the best outcome measures and it is essential that functional assessments should be included. An advantage of large multicenter trials is that they will provide more statistical power, enabling even subtle deficits that are still evident in the long term following ischemic damage to be used to reveal treatment effects, as highlighted recently by Rewell et al. [51]. However, to carry out behavioral assessments in this multicenter situation requires robust, standardized and centralized training of experimenters, especially if they are expected to apply a subjective scoring system. One way to avoid bias is to have scoring of behavioral videos carried out by experimenters blinded and in a centralized 
location. In practice, the selection of tests tends to be more challenging. There needs to be standardization, not only across sites for a single trial, but between trials to allow comparison of studies. This would mimic the clinical situation where standardized assessments such as the modified Rankin or Fugl-Meyer scales are used. The chosen test/s need/s to be suitable for multiple models of stroke and strains, should be easy to administer across multiple sites, be quantitative and objective, detect deficits in the longer term post-stroke and ideally enable high throughput testing. At present, no single behavioral test is adequate for capturing the range of stroke deficits and there is no consensus on what would represent the best test battery. Therefore, there is a need to improve current assessments or to develop new tests. These may rely on the types of kinematic analysis detailed earlier, or the use other sensitive equipment to detect subtle deficits, such as drinking behavior [154]. Until the point that these sorts of test and the technology become widely accessible, some type of compromise will be necessary. This may be achieved by using easily applicable tests that have some flaws across all sites and then having a subset of centers carrying out more detailed behavior tests within the trial.

\section{Toward better stroke recovery studies}

Implementing the optimal battery of behavioral tests is time-consuming and expansive. Behavioral tests are often performed by rotating personnel (e.g. undergraduate and graduate students). However, more consistent and reliable results will likely have to be obtained if one has well-trained personnel who have a strong background in behavioral assessment techniques. Improved function is the most important endpoint not only for stroke, but also for other neurodegenerative and cognitive disorders and this applies not only for academic institutions, but also for the pharmaceutical industry.

For-profit contract research organizations tend to lack the flexibility to adapt their

readout batteries to a desired specialized endpoint, or to even develop novel test components to specifically assess those outcomes. On the other hand, almost no academic research group and only a few universities can afford to invest in infrastructure and create research teams solely dedicated to the science of behavioral outcome measures. Future improvements in behavioral phenotyping for stroke research must therefore seek alternative solutions. For 
instance, the pharmaceutical industry and academic institutions may form a partnership to establish high-quality behavioral readout centers [155], which may also represent core elements of multicenter preclinical trials.

In addition, active interactions between basic scientists, nursing staff and clinicians are important in working towards a better stroke recovery research. One good example of this approach is the Stroke Recovery and Rehabilitation Roundtable (SRRR) which aims to provide recommendations for the preclinical modeling of stroke recovery and for the better alignment between preclinical and clinical researchers [156,157].

\section{Conclusion}

Past preclinical stroke research approaches in neuroprotection have been associated with complete translational failures. Hundreds of neuroprotective compounds seemingly effective in experimental models, have failed to work when administered to stroke patients. Thus, a major challenge will be to prevent this failure happening again by improving study quality and by carefully selecting clinically relevant stroke models and outcome measures. Sensitivity, the capability to differentiate long-term recovery from compensation and automation will undoubtedly be incorporated into an optimized behavioral test battery. In addition, we expect that behavioral testing will become an integral part of future preclinical multicenter studies. Accordingly, the tests need to be standardized to allow comparison of results from different centers, to increase statistical power and to decrease the overall study

costs. Finally, it can be anticipated that stroke recovery recommendations achieved through preclinical and clinical dialogues such as the SRRR will guide future research on the route to successful translation [156,157].

\section{References}

[1] L. Brewer, F. Horgan, A. Hickey, D. Williams, Stroke rehabilitation: recent advances and future therapies, QJM Mon. J. Assoc. Physicians. 106 (2013) 11-25. doi:10.1093/qjmed/hcs174.

[2] S.S. Kessner, U. Bingel, G. Thomalla, Somatosensory deficits after stroke: a scoping review, Top. Stroke Rehabil. 23 (2016) 136-146. doi:10.1080/10749357.2015.1116822. 
[3] C.M. Klingner, O.W. Witte, A. Günther, Sensory syndromes, Front. Neurol. Neurosci. 30 (2012) 48. doi:10.1159/000333373.

[4] S.C. Cramer, Repairing the human brain after stroke: I. Mechanisms of spontaneous recovery, Ann. Neurol. 63 (2008) 272-287. doi:10.1002/ana.21393.

[5] T.E. Twitchell, The restoration of motor function following hemiplegia in man, Brain J. Neurol. 74 (1951) 443-480.

[6] S.K. Wee, A.-M. Hughes, M. Warner, J.H. Burridge, Trunk restraint to promote upper extremity recovery in stroke patients: a systematic review and meta-analysis, Neurorehabil. Neural Repair. 28 (2014) 660-677. doi:10.1177/1545968314521011.

[7] A. Douiri, C. McKevitt, E.S. Emmett, A.G. Rudd, C.D.A. Wolfe, Long-term effects of secondary prevention on cognitive function in stroke patients, Circulation. 128 (2013) 1341-1348. doi:10.1161/CIRCULATIONAHA.113.002236.

[8] V.C.T. Mok, B.Y.K. Lam, A. Wong, H. Ko, H.S. Markus, L.K.S. Wong, Early-onset and delayed-onset poststroke dementia - revisiting the mechanisms, Nat. Rev. Neurol. 13 (2017) 148-159. doi:10.1038/nrneurol.2017.16.

[9] M.M. Breteler, Vascular risk factors for Alzheimer's disease: an epidemiologic perspective, Neurobiol. Aging. 21 (2000) 153-160.

[10] S.E. Starkstein, R.G. Robinson, Affective disorders and cerebral vascular disease, Br. J. Psychiatry J. Ment. Sci. 154 (1989) 170-182.

[11] J.S. Kim, Post-stroke Mood and Emotional Disturbances: Pharmacological Therapy Based on Mechanisms, J. Stroke. 18 (2016) 244-255. doi:10.5853/jos.2016.01144.

[12] L. De Wit, K. Putman, I. Baert, N.B. Lincoln, F. Angst, H. Beyens, K. Bogaerts, N. Brinkmann, L. Connell, E. Dejaeger, W. De Weerdt, W. Jenni, C. Kaske, A. Komarek, E. Lesaffre, M. Leys, F. Louckx, B. Schuback, W. Schupp, B. Smith, H. Feys, Anxiety and depression in the first six months after stroke. A longitudinal multicentre study, Disabil. Rehabil. 30 (2008) 1858-1866. doi:10.1080/09638280701708736.

[13] R.G. Robinson, G. Spalletta, Poststroke depression: a review, Can. J. Psychiatry Rev. Can. Psychiatr. 55 (2010) 341-349. doi:10.1177/070674371005500602.

[14] N.B. Lincoln, N. Brinkmann, S. Cunningham, E. Dejaeger, W. De Weerdt, W. Jenni, A. Mahdzir, K. Putman, W. Schupp, B. Schuback, L. De Wit, Anxiety and depression after stroke: a 5 year followup, Disabil. Rehabil. 35 (2013) 140-145. doi:10.3109/09638288.2012.691939.

[15] M. Janowski, D.-C. Wagner, J. Boltze, Stem Cell-Based Tissue Replacement After Stroke: Factual Necessity or Notorious Fiction?, Stroke. 46 (2015) 2354-2363. doi:10.1161/STROKEAHA.114.007803.

[16] S.T. Carmichael, Emergent properties of neural repair: elemental biology to therapeutic concepts, Ann. Neurol. 79 (2016) 895-906. doi:10.1002/ana.24653.

[17] D.M. Hermann, M. Chopp, Promoting brain remodelling and plasticity for stroke recovery: therapeutic promise and potential pitfalls of clinical translation, Lancet Neurol. 11 (2012) 369380. doi:10.1016/S1474-4422(12)70039-X.

[18] T.H. Murphy, D. Corbett, Plasticity during stroke recovery: from synapse to behaviour, Nat. Rev. Neurosci. 10 (2009) 861-872. doi:10.1038/nrn2735.

[19] J.W. Krakauer, S.T. Carmichael, D. Corbett, G.F. Wittenberg, Getting neurorehabilitation right: what can be learned from animal models?, Neurorehabil. Neural Repair. 26 (2012) 923-931. doi:10.1177/1545968312440745.

[20] J. Boltze, F. Nitzsche, J. Jolkkonen, G. Weise, C. Pösel, B. Nitzsche, D.-C. Wagner, Concise review: Increasing the validity of cerebrovascular disease models and experimental methods for translational stem cell research, Stem Cells Dayt. Ohio. (2017). doi:10.1002/stem.2595. 
[21] D.W. Howells, M.J. Porritt, S.S.J. Rewell, V. O'Collins, E.S. Sena, H.B. van der Worp, R.J. Traystman, M.R. Macleod, Different strokes for different folks: the rich diversity of animal models of focal cerebral ischemia, J. Cereb. Blood Flow Metab. Off. J. Int. Soc. Cereb. Blood Flow Metab. 30 (2010) 1412-1431. doi:10.1038/jcbfm.2010.66.

[22] J.O. Ström, E. Ingberg, A. Theodorsson, E. Theodorsson, Method parameters' impact on mortality and variability in rat stroke experiments: a meta-analysis, BMC Neurosci. 14 (2013) 41. doi:10.1186/1471-2202-14-41.

[23] S. Tétrault, O. Chever, A. Sik, F. Amzica, Opening of the blood-brain barrier during isoflurane anaesthesia, Eur. J. Neurosci. 28 (2008) 1330-1341. doi:10.1111/j.1460-9568.2008.06443.x.

[24] L. Xiong, Y. Zheng, M. Wu, L. Hou, Z. Zhu, X. Zhang, Z. Lu, Preconditioning with isoflurane produces dose-dependent neuroprotection via activation of adenosine triphosphate-regulated potassium channels after focal cerebral ischemia in rats, Anesth. Analg. 96 (2003) 233-237, table of contents.

[25] C.L. Ryan, T.A. Doucette, D.A. Gill, K.D. Langdon, Y. Liu, M.A. Perry, R.A. Tasker, An improved postoperative care protocol allows detection of long-term functional deficits following MCAo surgery in rats, J. Neurosci. Methods. 154 (2006) 30-37. doi:10.1016/j.jneumeth.2005.11.009.

[26] M. Dittmar, T. Spruss, G. Schuierer, M. Horn, External carotid artery territory ischemia impairs outcome in the endovascular filament model of middle cerebral artery occlusion in rats, Stroke J. Cereb. Circ. 34 (2003) 2252-2257. doi:10.1161/01.STR.0000083625.54851.9A.

[27] G. Kalesnykas, T. Tuulos, H. Uusitalo, J. Jolkkonen, Neurodegeneration and cellular stress in the retina and optic nerve in rat cerebral ischemia and hypoperfusion models, Neuroscience. 155 (2008) 937-947. doi:10.1016/j.neuroscience.2008.06.038.

[28] R.C. Trueman, D.J. Harrison, D.M. Dwyer, S.B. Dunnett, M. Hoehn, T.D. Farr, A Critical ReExamination of the Intraluminal Filament MCAO Model: Impact of External Carotid Artery Transection, Transl. Stroke Res. 2 (2011) 651-661. doi:10.1007/s12975-011-0102-4.

[29] S. Mering, J. Jolkkonen, Proper housing conditions in experimental stroke studies-special emphasis on environmental enrichment, Front. Neurosci. 9 (2015) 106. doi:10.3389/fnins.2015.00106.

[30] M. Balkaya, J. Kröber, K. Gertz, S. Peruzzaro, M. Endres, Characterization of long-term functional outcome in a murine model of mild brain ischemia, J. Neurosci. Methods. 213 (2013) 179-187. doi:10.1016/j.jneumeth.2012.12.021.

[31] M. Balkaya, J.M. Kröber, A. Rex, M. Endres, Assessing post-stroke behavior in mouse models of focal ischemia, J. Cereb. Blood Flow Metab. Off. J. Int. Soc. Cereb. Blood Flow Metab. 33 (2013) 330-338. doi:10.1038/jcbfm.2012.185.

[32] J. Boltze, B. Lukomska, J. Jolkkonen, MEMS-IRBI consortium, Mesenchymal stromal cells in stroke: improvement of motor recovery or functional compensation?, J. Cereb. Blood Flow Metab. Off. J. Int. Soc. Cereb. Blood Flow Metab. 34 (2014) 1420-1421. doi:10.1038/jcbfm.2014.94.

[33] J.A. Kleim, J.A. Boychuk, D.L. Adkins, Rat models of upper extremity impairment in stroke, ILAR J. 48 (2007) 374-384.

[34] K.L. Schaar, M.M. Brenneman, S.I. Savitz, Functional assessments in the rodent stroke model, Exp. Transl. Stroke Med. 2 (2010) 13. doi:10.1186/2040-7378-2-13.

[35] A. Lipsanen, J. Jolkkonen, Experimental approaches to study functional recovery following cerebral ischemia, Cell. Mol. Life Sci. CMLS. 68 (2011) 3007-3017. doi:10.1007/s00018-011-07333.

[36] R.C. Trueman, C. Diaz, T.D. Farr, D.J. Harrison, A. Fuller, P.F. Tokarczuk, A.J. Stewart, S.J. Paisey, S.B. Dunnett, Systematic and detailed analysis of behavioural tests in the rat middle cerebral 
artery occlusion model of stroke: Tests for long-term assessment, J. Cereb. Blood Flow Metab. Off. J. Int. Soc. Cereb. Blood Flow Metab. 37 (2017) 1349-1361. doi:10.1177/0271678X16654921.

[37] Y. Li, J. Chen, L. Wang, M. Lu, M. Chopp, Treatment of stroke in rat with intracarotid administration of marrow stromal cells, Neurology. 56 (2001) 1666-1672.

[38] A. Encarnacion, N. Horie, H. Keren-Gill, T.M. Bliss, G.K. Steinberg, M. Shamloo, Long-term behavioral assessment of function in an experimental model for ischemic stroke, J. Neurosci. Methods. 196 (2011) 247-257. doi:10.1016/j.jneumeth.2011.01.010.

[39] E. Ingberg, J. Gudjonsdottir, E. Theodorsson, A. Theodorsson, J.O. Ström, Elevated body swing test after focal cerebral ischemia in rodents: methodological considerations, BMC Neurosci. 16 (2015) 50. doi:10.1186/s12868-015-0189-8.

[40] J. Jolkkonen, K. Puurunen, S. Rantakömi, A. Härkönen, A. Haapalinna, J. Sivenius, Behavioral effects of the alpha(2)-adrenoceptor antagonist, atipamezole, after focal cerebral ischemia in rats, Eur. J. Pharmacol. 400 (2000) 211-219.

[41] M. De Ryck, J. Van Reempts, H. Duytschaever, B. Van Deuren, G. Clincke, Neocortical localization of tactile/proprioceptive limb placing reactions in the rat, Brain Res. 573 (1992) 44-60.

[42] T. Schallert, M.T. Woodlee, Orienting and placing, in: Behav. Lab. Rat, Edited Whishaw IQ, Kolb B, Oxford University Press, 2005: pp. 129-140.

[43] D.C. Rogers, E.M. Fisher, S.D. Brown, J. Peters, A.J. Hunter, J.E. Martin, Behavioral and functional analysis of mouse phenotype: SHIRPA, a proposed protocol for comprehensive phenotype assessment, Mamm. Genome Off. J. Int. Mamm. Genome Soc. 8 (1997) 711-713.

[44] G.W. Arbuthnott, U. Ungerstedt, Turning behavior induced by electrical stimulation of the nigroneostriatal system of the rat, Exp. Neurol. 47 (1975) 162-172.

[45] T. Veizovic, J.S. Beech, R.P. Stroemer, W.P. Watson, H. Hodges, Resolution of stroke deficits following contralateral grafts of conditionally immortal neuroepithelial stem cells, Stroke. 32 (2001) 1012-1019.

[46] M. Modo, R.P. Stroemer, E. Tang, S. Patel, H. Hodges, Effects of implantation site of stem cell grafts on behavioral recovery from stroke damage, Stroke. 33 (2002) 2270-2278.

[47] M. Grabowski, P. Brundin, B.B. Johansson, Paw-reaching, sensorimotor, and rotational behavior after brain infarction in rats, Stroke. 24 (1993) 889-895.

[48] J. Linden, L. Van de Beeck, J.-C. Plumier, A. Ferrara, Procedural learning as a measure of functional impairment in a mouse model of ischemic stroke, Behav. Brain Res. 307 (2016) 35-45. doi:10.1016/j.bbr.2016.03.032.

[49] T. Schallert, I.Q. Whishaw, Bilateral cutaneous stimulation of the somatosensory system in hemidecorticate rats, Behav. Neurosci. 98 (1984) 518-540.

[50] V. Bouët, T. Freret, J. Toutain, D. Divoux, M. Boulouard, P. Schumann-Bard, Sensorimotor and cognitive deficits after transient middle cerebral artery occlusion in the mouse, Exp. Neurol. 203 (2007) 555-567. doi:10.1016/j.expneurol.2006.09.006.

[51] S.S.J. Rewell, L. Churilov, T.K. Sidon, E. Aleksoska, S.F. Cox, M.R. Macleod, D.W. Howells, Evolution of ischemic damage and behavioural deficit over 6 months after MCAo in the rat: Selecting the optimal outcomes and statistical power for multi-centre preclinical trials, PloS One. 12 (2017) e0171688. doi:10.1371/journal.pone.0171688.

[52] R.J. Hamm, B.R. Pike, D.M. O'Dell, B.G. Lyeth, L.W. Jenkins, The rotarod test: an evaluation of its effectiveness in assessing motor deficits following traumatic brain injury, J. Neurotrauma. 11 (1994) 187-196.

[53] J. Chen, Y. Li, L. Wang, Z. Zhang, D. Lu, M. Lu, M. Chopp, Therapeutic benefit of intravenous administration of bone marrow stromal cells after cerebral ischemia in rats, Stroke. 32 (2001) 1005-1011. 
[54] F. Erdo, P. Berzsenyi, L. Német, F. Andrási, Talampanel improves the functional deficit after transient focal cerebral ischemia in rats. A 30-day follow up study, Brain Res. Bull. 68 (2006) 269276. doi:10.1016/j.brainresbull.2005.08.018.

[55] A. Kunze, D. Zierath, O. Drogomiretskiy, K. Becker, Variation in behavioral deficits and patterns of recovery after stroke among different rat strains, Transl. Stroke Res. 5 (2014) 569-576. doi:10.1007/s12975-014-0337-y.

[56] H. Karhunen, T. Virtanen, T. Schallert, J. Sivenius, J. Jolkkonen, Forelimb use after focal cerebral ischemia in rats treated with an alpha 2-adrenoceptor antagonist, Pharmacol. Biochem. Behav. 74 (2003) 663-669.

[57] L. Zhang, T. Schallert, Z.G. Zhang, Q. Jiang, P. Arniego, Q. Li, M. Lu, M. Chopp, A test for detecting long-term sensorimotor dysfunction in the mouse after focal cerebral ischemia, J. Neurosci. Methods. 117 (2002) 207-214.

[58] B. Manwani, F. Liu, Y. Xu, R. Persky, J. Li, L.D. McCullough, Functional recovery in aging mice after experimental stroke, Brain. Behav. Immun. 25 (2011) 1689-1700. doi:10.1016/j.bbi.2011.06.015.

[59] T.R. Doeppner, B. Kaltwasser, M. Bähr, D.M. Hermann, Effects of neural progenitor cells on poststroke neurological impairment-a detailed and comprehensive analysis of behavioral tests, Front. Cell. Neurosci. 8 (2014) 338. doi:10.3389/fncel.2014.00338.

[60] K.A. Tennant, T.A. Jones, Sensorimotor behavioral effects of endothelin-1 induced small cortical infarcts in C57BL/6 mice, J. Neurosci. Methods. 181 (2009) 18-26. doi:10.1016/j.jneumeth.2009.04.009.

[61] T. Freret, V. Bouet, C. Leconte, S. Roussel, L. Chazalviel, D. Divoux, P. Schumann-Bard, M. Boulouard, Behavioral deficits after distal focal cerebral ischemia in mice: Usefulness of adhesive removal test, Behav. Neurosci. 123 (2009) 224-230. doi:10.1037/a0014157.

[62] J. Lubjuhn, A. Gastens, G. von Wilpert, P. Bargiotas, O. Herrmann, S. Murikinati, T. Rabie, H.H. Marti, H. Marti, I. Amende, T.G. Hampton, M. Schwaninger, Functional testing in a mouse stroke model induced by occlusion of the distal middle cerebral artery, J. Neurosci. Methods. 184 (2009) 95-103. doi:10.1016/j.jneumeth.2009.07.029.

[63] C.P. Montoya, L.J. Campbell-Hope, K.D. Pemberton, S.B. Dunnett, The "staircase test": a measure of independent forelimb reaching and grasping abilities in rats, J. Neurosci. Methods. 36 (1991) 219-228.

[64] C.L. MacLellan, M.B. Keough, S. Granter-Button, G.A. Chernenko, S. Butt, D. Corbett, A critical threshold of rehabilitation involving brain-derived neurotrophic factor is required for poststroke recovery, Neurorehabil. Neural Repair. 25 (2011) 740-748. doi:10.1177/1545968311407517.

[65] M.S. Jeffers, A. Hoyles, C. Morshead, D. Corbett, Epidermal growth factor and erythropoietin infusion accelerate functional recovery in combination with rehabilitation, Stroke J. Cereb. Circ. 45 (2014) 1856-1858. doi:10.1161/STROKEAHA.114.005464.

[66] O.A. Gharbawie, C.L.R. Gonzalez, I.Q. Whishaw, Skilled reaching impairments from the lateral frontal cortex component of middle cerebral artery stroke: a qualitative and quantitative comparison to focal motor cortex lesions in rats, Behav. Brain Res. 156 (2005) 125-137. doi:10.1016/j.bbr.2004.05.015.

[67] I.Q. Whishaw, M. Alaverdashvili, B. Kolb, The problem of relating plasticity and skilled reaching after motor cortex stroke in the rat, Behav. Brain Res. 192 (2008) 124-136. doi:10.1016/j.bbr.2007.12.026.

[68] M. Alaverdashvili, I.Q. Whishaw, A behavioral method for identifying recovery and compensation: hand use in a preclinical stroke model using the single pellet reaching task, Neurosci. Biobehav. Rev. 37 (2013) 950-967. doi:10.1016/j.neubiorev.2013.03.026. 
[69] M. Knieling, G.A. Metz, I. Antonow-Schlorke, O.W. Witte, Enriched environment promotes efficiency of compensatory movements after cerebral ischemia in rats, Neuroscience. 163 (2009) 759-769. doi:10.1016/j.neuroscience.2009.07.004.

[70] T.D. Farr, I.Q. Whishaw, Quantitative and qualitative impairments in skilled reaching in the mouse (Mus musculus) after a focal motor cortex stroke, Stroke. 33 (2002) 1869-1875.

[71] A. Klein, S.B. Dunnett, Analysis of skilled forelimb movement in rats: the single pellet reaching test and staircase test, Curr. Protoc. Neurosci. Chapter 8 (2012) Unit8.28. doi:10.1002/0471142301.ns0828s58.

[72] R.P. Allred, D.L. Adkins, M.T. Woodlee, L.C. Husbands, M.A. Maldonado, J.R. Kane, T. Schallert, T.A. Jones, The vermicelli handling test: a simple quantitative measure of dexterous forepaw function in rats, J. Neurosci. Methods. 170 (2008) 229-244. doi:10.1016/j.jneumeth.2008.01.015.

[73] T. van Groen, K. Puurunen, H.-M. Mäki, J. Sivenius, J. Jolkkonen, Transformation of diffuse betaamyloid precursor protein and beta-amyloid deposits to plaques in the thalamus after transient occlusion of the middle cerebral artery in rats, Stroke J. Cereb. Circ. 36 (2005) 1551-1556. doi:10.1161/01.STR.0000169933.88903.cf.

[74] G.A. Metz, I.Q. Whishaw, Cortical and subcortical lesions impair skilled walking in the ladder rung walking test: a new task to evaluate fore- and hindlimb stepping, placing, and co-ordination, J. Neurosci. Methods. 115 (2002) 169-179.

[75] E.V. Shanina, T. Schallert, O.W. Witte, C. Redecker, Behavioral recovery from unilateral photothrombotic infarcts of the forelimb sensorimotor cortex in rats: role of the contralateral cortex, Neuroscience. 139 (2006) 1495-1506. doi:10.1016/j.neuroscience.2006.01.016.

[76] B. Balaban, F. Tok, Gait disturbances in patients with stroke, PM R. 6 (2014) 635-642. doi:10.1016/j.pmrj.2013.12.017.

[77] C. Beyaert, R. Vasa, G.E. Frykberg, Gait post-stroke: Pathophysiology and rehabilitation strategies, Neurophysiol. Clin. Clin. Neurophysiol. 45 (2015) 335-355. doi:10.1016/j.neucli.2015.09.005.

[78] M.M. Inserra, D.A. Bloch, D.J. Terris, Functional indices for sciatic, peroneal, and posterior tibial nerve lesions in the mouse, Microsurgery. 18 (1998) 119-124.

[79] F.P.T. Hamers, G.C. Koopmans, E.A.J. Joosten, CatWalk-assisted gait analysis in the assessment of spinal cord injury, J. Neurotrauma. 23 (2006) 537-548. doi:10.1089/neu.2006.23.537.

[80] S. Hetze, C. Römer, C. Teufelhart, A. Meisel, O. Engel, Gait analysis as a method for assessing neurological outcome in a mouse model of stroke, J. Neurosci. Methods. 206 (2012) 7-14. doi:10.1016/j.jneumeth.2012.02.001.

[81] Y. Cao, N. Sun, J.-W. Yang, Y. Zheng, W. Zhu, Z.-H. Zhang, X.-R. Wang, G.-X. Shi, C.-Z. Liu, Does acupuncture ameliorate motor impairment after stroke? An assessment using the CatWalk gait system, Neurochem. Int. (2016). doi:10.1016/j.neuint.2016.10.014.

[82] Y. Wang, B. Bontempi, S.M. Hong, K. Mehta, P.R. Weinstein, G.M. Abrams, J. Liu, A comprehensive analysis of gait impairment after experimental stroke and the therapeutic effect of environmental enrichment in rats, J. Cereb. Blood Flow Metab. Off. J. Int. Soc. Cereb. Blood Flow Metab. 28 (2008) 1936-1950. doi:10.1038/jcbfm.2008.82.

[83] S. Li, Z. Shi, H. Zhang, X. Liu, S. Chen, J. Jin, Y. Wang, W. Jia, H. Li, Assessing gait impairment after permanent middle cerebral artery occlusion in rats using an automated computer-aided control system, Behav. Brain Res. 250 (2013) 174-191. doi:10.1016/j.bbr.2013.04.044.

[84] E. Kim, M.-S. Woo, L. Qin, T. Ma, C.D. Beltran, Y. Bao, J.A. Bailey, D. Corbett, R.R. Ratan, D.K. Lahiri, S. Cho, Daidzein Augments Cholesterol Homeostasis via ApoE to Promote Functional Recovery in Chronic Stroke, J. Neurosci. Off. J. Soc. Neurosci. 35 (2015) 15113-15126. doi:10.1523/JNEUROSCI.2890-15.2015. 
[85] S. Parkkinen, F.J. Ortega, K. Kuptsova, J. Huttunen, I. Tarkka, J. Jolkkonen, Gait impairment in a rat model of focal cerebral ischemia, Stroke Res. Treat. 2013 (2013) 410972. doi:10.1155/2013/410972.

[86] A. de los Reyes-Guzmán, I. Dimbwadyo-Terrer, F. Trincado-Alonso, F. Monasterio-Huelin, D. Torricelli, A. Gil-Agudo, Quantitative assessment based on kinematic measures of functional impairments during upper extremity movements: A review, Clin. Biomech. Bristol Avon. 29 (2014) 719-727. doi:10.1016/j.clinbiomech.2014.06.013.

[87] G. Verheyden, H.J.R. van Duijnhoven, M. Burnett, J. Littlewood, D. Kunkel, A.M. Ashburn, Stroke Association Rehabilitation Research Centre, Kinematic analysis of head, trunk, and pelvis movement when people early after stroke reach sideways, Neurorehabil. Neural Repair. 25 (2011) 656-663. doi:10.1177/1545968311401628.

[88] M.D. Lewek, T.H. Cruz, J.L. Moore, H.R. Roth, Y.Y. Dhaher, T.G. Hornby, Allowing intralimb kinematic variability during locomotor training poststroke improves kinematic consistency: a subgroup analysis from a randomized clinical trial, Phys. Ther. 89 (2009) 829-839. doi:10.2522/ptj.20080180.

[89] C.-Y. Wu, R.-J. Liing, H.-C. Chen, C.-L. Chen, K.-C. Lin, Arm and trunk movement kinematics during seated reaching within and beyond arm's length in people with stroke: a validity study, Phys. Ther. 94 (2014) 845-856. doi:10.2522/ptj.20130101.

[90] L. Mandon, J. Boudarham, J. Robertson, D. Bensmail, N. Roche, A. Roby-Brami, Faster Reaching in Chronic Spastic Stroke Patients Comes at the Expense of Arm-Trunk Coordination, Neurorehabil. Neural Repair. 30 (2016) 209-220. doi:10.1177/1545968315591704.

[91] A.A. Webb, B. Kerr, T. Neville, S. Ngan, H. Assem, Kinematics and ground reaction force determination: a demonstration quantifying locomotor abilities of young adult, middle-aged, and geriatric rats, J. Vis. Exp. JoVE. (2011). doi:10.3791/2138.

[92] G.B. Gillis, R.W. Blob, How muscles accommodate movement in different physical environments: aquatic vs. terrestrial locomotion in vertebrates, Comp. Biochem. Physiol. A. Mol. Integr. Physiol. 131 (2001) 61-75.

[93] R.M. Walter, Kinematics of 90 degrees running turns in wild mice, J. Exp. Biol. 206 (2003) 17391749.

[94] M. Bojados, M. Herbin, M. Jamon, Kinematics of treadmill locomotion in mice raised in hypergravity, Behav. Brain Res. 244 (2013) 48-57. doi:10.1016/j.bbr.2013.01.017.

[95] Y. Cheong, R.L. Shehab, C. Ling, Effects of age and psychomotor ability on kinematics of mousemediated aiming movement, Ergonomics. 56 (2013) 1006-1020. doi:10.1080/00140139.2013.781682.

[96] O. Perrot, D. Laroche, T. Pozzo, C. Marie, Quantitative assessment of stereotyped and challenged locomotion after lesion of the striatum: a 3D kinematic study in rats, PloS One. 4 (2009) e7616. doi:10.1371/journal.pone.0007616.

[97] T. Eftaxiopoulou, W. Macdonald, D. Britzman, A.M.J. Bull, Gait compensations in rats after a temporary nerve palsy quantified using temporo-spatial and kinematic parameters, J. Neurosci. Methods. 232 (2014) 16-23. doi:10.1016/j.jneumeth.2014.04.011.

[98] R.G. Braun, E.M. Andrews, G.L. Kartje, Kinematic analysis of motor recovery with human adult bone marrow-derived somatic cell therapy in a rat model of stroke, Neurorehabil. Neural Repair. 26 (2012) 898-906. doi:10.1177/1545968312446004.

[99] S. Lai, A. Panarese, C. Spalletti, C. Alia, A. Ghionzoli, M. Caleo, S. Micera, Quantitative kinematic characterization of reaching impairments in mice after a stroke, Neurorehabil. Neural Repair. 29 (2015) 382-392. doi:10.1177/1545968314545174. 
[100] M. Alaverdashvili, A. Foroud, D.H. Lim, I.Q. Whishaw, "Learned baduse" limits recovery of skilled reaching for food after forelimb motor cortex stroke in rats: a new analysis of the effect of gestures on success, Behav. Brain Res. 188 (2008) 281-290. doi:10.1016/j.bbr.2007.11.007.

[101] R. Morris, Developments of a water-maze procedure for studying spatial learning in the rat, J. Neurosci. Methods. 11 (1984) 47-60.

[102] W. Li, R. Huang, R.A. Shetty, N. Thangthaeng, R. Liu, Z. Chen, N. Sumien, M. Rutledge, G.H. Dillon, F. Yuan, M.J. Forster, J.W. Simpkins, S.-H. Yang, Transient focal cerebral ischemia induces longterm cognitive function deficit in an experimental ischemic stroke model, Neurobiol. Dis. 59 (2013) 18-25. doi:10.1016/j.nbd.2013.06.014.

[103] K. Puurunen, J. Jolkkonen, J. Sirviö, A. Haapalinna, J. Sivenius, Selegiline combined with enrichedenvironment housing attenuates spatial learning deficits following focal cerebral ischemia in rats, Exp. Neurol. 167 (2001) 348-355. doi:10.1006/exnr.2000.7563.

[104] D. Bingham, S.J. Martin, I.M. Macrae, H.V.O. Carswell, Watermaze performance after middle cerebral artery occlusion in the rat: the role of sensorimotor versus memory impairments, J. Cereb. Blood Flow Metab. Off. J. Int. Soc. Cereb. Blood Flow Metab. 32 (2012) 989-999. doi:10.1038/jcbfm.2012.16.

[105] I.Q. Whishaw, J.A. Tomie, Of mice and mazes: similarities between mice and rats on dry land but not water mazes, Physiol. Behav. 60 (1996) 1191-1197.

[106] H. livonen, L. Nurminen, M. Harri, H. Tanila, J. Puoliväli, Hypothermia in mice tested in Morris water maze, Behav. Brain Res. 141 (2003) 207-213.

[107] C.V. Vorhees, M.T. Williams, Assessing spatial learning and memory in rodents, ILAR J. 55 (2014) 310-332. doi:10.1093/ilar/ilu013.

[108] J. Clarke, A. Thornell, D. Corbett, H. Soininen, M. Hiltunen, J. Jolkkonen, Overexpression of APP provides neuroprotection in the absence of functional benefit following middle cerebral artery occlusion in rats, Eur. J. Neurosci. 26 (2007) 1845-1852. doi:10.1111/j.1460-9568.2007.05807.x.

[109] Y. Chin, M. Kishi, M. Sekino, F. Nakajo, Y. Abe, Y. Terazono, O. Hiroyuki, F. Kato, S. Koizumi, C. Gachet, T. Hisatsune, Involvement of glial P2 ${ }_{1}$ receptors in cognitive deficit after focal cerebral stroke in a rodent model, J. Neuroinflammation. 10 (2013) 95. doi:10.1186/1742-2094-10-95.

[110] H. Shimada, M. Hamakawa, A. Ishida, K. Tamakoshi, H. Nakashima, K. Ishida, Low-speed treadmill running exercise improves memory function after transient middle cerebral artery occlusion in rats, Behav. Brain Res. 243 (2013) 21-27. doi:10.1016/j.bbr.2012.12.018.

[111] K. Hattori, H. Lee, P.D. Hurn, B.J. Crain, R.J. Traystman, A.C. DeVries, Cognitive deficits after focal cerebral ischemia in mice, Stroke. 31 (2000) 1939-1944.

[112] A.E. Willing, L. Jiang, P. Nowicki, S. Poulos, M. Milliken, D.W. Cahill, P.R. Sanberg, Effects of middle cerebral artery occlusion on spontaneous activity and cognitive function in rats, Int. J. Neurosci. 112 (2002) 503-516.

[113] V. Kumar, Z.A. Bhat, D. Kumar, Animal models of anxiety: a comprehensive review, J. Pharmacol. Toxicol. Methods. 68 (2013) 175-183. doi:10.1016/j.vascn.2013.05.003.

[114] R.D. Porsolt, Animal models of depression: utility for transgenic research, Rev. Neurosci. 11 (2000) 53-58.

[115] R.D. Porsolt, A. Bertin, M. Jalfre, Behavioral despair in mice: a primary screening test for antidepressants, Arch. Int. Pharmacodyn. Ther. 229 (1977) 327-336.

[116] J.F. Cryan, C. Mombereau, A. Vassout, The tail suspension test as a model for assessing antidepressant activity: review of pharmacological and genetic studies in mice, Neurosci. Biobehav. Rev. 29 (2005) 571-625. doi:10.1016/j.neubiorev.2005.03.009.

[117] J.L. Moreau, Reliable monitoring of hedonic deficits in the chronic mild stress model of depression, Psychopharmacology (Berl.). 134 (1997) 357-358; discussion 371-377. 
[118] P. Willner, R. Muscat, M. Papp, Chronic mild stress-induced anhedonia: a realistic animal model of depression, Neurosci. Biobehav. Rev. 16 (1992) 525-534.

[119] F. Vahid-Ansari, D.C. Lagace, P.R. Albert, Persistent post-stroke depression in mice following unilateral medial prefrontal cortical stroke, Transl. Psychiatry. 6 (2016) e863. doi:10.1038/tp.2016.124.

[120] B. Winter, G. Juckel, I. Viktorov, J. Katchanov, A. Gietz, R. Sohr, M. Balkaya, H. Hörtnagl, M. Endres, Anxious and hyperactive phenotype following brief ischemic episodes in mice, Biol. Psychiatry. 57 (2005) 1166-1175. doi:10.1016/j.biopsych.2005.02.010.

[121] G. Kronenberg, M. Balkaya, V. Prinz, K. Gertz, S. Ji, I. Kirste, I. Heuser, B. Kampmann, J. HellmannRegen, P. Gass, R. Sohr, R. Hellweg, C. Waeber, G. Juckel, H. Hörtnagl, R. Stumm, M. Endres, Exofocal dopaminergic degeneration as antidepressant target in mouse model of poststroke depression, Biol. Psychiatry. 72 (2012) 273-281. doi:10.1016/j.biopsych.2012.02.026.

[122] T.K.S. Craft, A.C. DeVries, Role of IL-1 in poststroke depressive-like behavior in mice, Biol. Psychiatry. 60 (2006) 812-818. doi:10.1016/j.biopsych.2006.03.011.

[123] Y.R. Kim, H.N. Kim, M.E. Pak, S.M. Ahn, K.H. Hong, H.K. Shin, B.T. Choi, Studies on the animal model of post-stroke depression and application of antipsychotic aripiprazole, Behav. Brain Res. 287 (2015) 294-303. doi:10.1016/j.bbr.2015.03.062.

[124] L.M. O'Keefe, S.J. Doran, L. Mwilambwe-Tshilobo, L.H. Conti, V.R. Venna, L.D. McCullough, Social isolation after stroke leads to depressive-like behavior and decreased BDNF levels in mice, Behav. Brain Res. 260 (2014) 162-170. doi:10.1016/j.bbr.2013.10.047.

[125] L. Niu, X. Jin, L. Jin, Y. Zhang, B. Liu, C. Li, Feasibility of focal cerebral ischemia and reperfusion surgery combined with chronic unpredictable mild stress to simulate the post-stroke depressive state in rats, Behav. Brain Funct. BBF. 11 (2015) 39. doi:10.1186/s12993-015-0085-5.

[126] M. Kato, H. Iwata, M. Okamoto, T. Ishii, H. Narita, Focal cerebral ischemia-induced escape deficit in rats is ameliorated by a reversible inhibitor of monoamine oxidase-a: implications for a novel animal model of post-stroke depression, Biol. Pharm. Bull. 23 (2000) 406-410.

[127] B. Shao, Y.L. Zhou, H. Wang, Y.S. Lin, The role of calcitonin gene-related peptide in post-stroke depression in chronic mild stress-treated ischemic rats, Physiol. Behav. 139 (2015) 224-230. doi:10.1016/j.physbeh.2014.11.049.

[128] S. Wang, Z. Zhang, Y. Guo, G. Teng, B. Chen, Decreased expression of serotonin 1A receptor in the dentate gyrus in association with chronic mild stress: a rat model of post-stroke depression, Psychiatry Res. 170 (2009) 245-251. doi:10.1016/j.psychres.2008.07.006.

[129] P. Willner, Chronic mild stress (CMS) revisited: consistency and behavioural-neurobiological concordance in the effects of CMS, Neuropsychobiology. 52 (2005) 90-110. doi:10.1159/000087097.

[130] A. Ieraci, A. Mallei, M. Popoli, Social Isolation Stress Induces Anxious-Depressive-Like Behavior and Alterations of Neuroplasticity-Related Genes in Adult Male Mice, Neural Plast. 2016 (2016) 6212983. doi:10.1155/2016/6212983.

[131] G.R. Cojocaru, A. Popa-Wagner, E.C. Stanciulescu, L. Babadan, A.-M. Buga, Post-stroke depression and the aging brain, J. Mol. Psychiatry. 1 (2013) 14. doi:10.1186/2049-9256-1-14.

[132] A.-M. Buga, O. Ciobanu, G.M. Bădescu, C. Bogdan, R. Weston, M. Slevin, M. Di Napoli, A. PopaWagner, Up-regulation of serotonin receptor 2B mRNA and protein in the peri-infarcted area of aged rats and stroke patients, Oncotarget. 7 (2016) 17415-17430. doi:10.18632/oncotarget.8277.

[133] B. Buchhold, L. Mogoanta, Y. Suofu, A. Hamm, L. Walker, C. Kessler, A. Popa-Wagner, Environmental enrichment improves functional and neuropathological indices following stroke in young and aged rats, Restor. Neurol. Neurosci. 25 (2007) 467-484. 
[134] C.C. Wong, D.S. Ramanathan, T. Gulati, S.J. Won, K. Ganguly, An automated behavioral box to assess forelimb function in rats, J. Neurosci. Methods. 246 (2015) 30-37. doi:10.1016/j.jneumeth.2015.03.008.

[135] K.K. Fenrich, Z. May, A. Torres-Espín, J. Forero, D.J. Bennett, K. Fouad, Single pellet grasping following cervical spinal cord injury in adult rat using an automated full-time training robot, Behav. Brain Res. 299 (2016) 59-71. doi:10.1016/j.bbr.2015.11.020.

[136] C.A. Cordova, D. Jackson, K.D. Langdon, K.A. Hewlett, D. Corbett, Impaired executive function following ischemic stroke in the rat medial prefrontal cortex, Behav. Brain Res. 258 (2014) 106111. doi:10.1016/j.bbr.2013.10.022.

[137] M. Rivalan, H. Munawar, A. Fuchs, Y. Winter, An Automated, Experimenter-Free Method for the Standardised, Operant Cognitive Testing of Rats, PloS One. 12 (2017) e0169476. doi:10.1371/journal.pone.0169476.

[138] A.H. Hainsworth, S.M. Allan, J. Boltze, C. Cunningham, C. Farris, E. Head, M. Ihara, J.D. Isaacs, R.N. Kalaria, S.A.M.J. Lesnik Oberstein, M.B. Moss, B. Nitzsche, G.A. Rosenberg, J.W. Rutten, M. Salkovic-Petrisic, A.M. Troen, Translational models for vascular cognitive impairment: a review including larger species, BMC Med. 15 (2017) 16. doi:10.1186/s12916-017-0793-9.

[139] P. Werner, D. Saur, V. Zeisig, B. Ettrich, M. Patt, B. Sattler, T. Jochimsen, D. Lobsien, P.M. Meyer, F.T. Bergh, A. Dreyer, J. Boltze, J. Classen, D. Fritzsch, K.-T. Hoffmann, O. Sabri, H. Barthel, Simultaneous PET/MRI in stroke: a case series, J. Cereb. Blood Flow Metab. Off. J. Int. Soc. Cereb. Blood Flow Metab. 35 (2015) 1421-1425. doi:10.1038/jcbfm.2015.158.

[140] J. Boltze, A. Förschler, B. Nitzsche, D. Waldmin, A. Hoffmann, C.M. Boltze, A.Y. Dreyer, A. Goldammer, A. Reischauer, W. Härtig, K.D. Geiger, H. Barthel, F. Emmrich, U. Gille, Permanent middle cerebral artery occlusion in sheep: a novel large animal model of focal cerebral ischemia, J. Cereb. Blood Flow Metab. Off. J. Int. Soc. Cereb. Blood Flow Metab. 28 (2008) 1951-1964. doi:10.1038/jcbfm.2008.89.

[141] K.J. Duberstein, S.R. Platt, S.P. Holmes, C.R. Dove, E.W. Howerth, M. Kent, S.L. Stice, W.D. Hill, D.C. Hess, F.D. West, Gait analysis in a pre- and post-ischemic stroke biomedical pig model, Physiol. Behav. 125 (2014) 8-16. doi:10.1016/j.physbeh.2013.11.004.

[142] F. Schmidt, J. Boltze, C. Jäger, S. Hofmann, N. Willems, J. Seeger, W. Härtig, A. Stolzing, Detection and Quantification of $\beta$-Amyloid, Pyroglutamyl $A \beta$, and Tau in Aged Canines, J. Neuropathol. Exp. Neurol. 74 (2015) 912-923. doi:10.1097/NEN.0000000000000230.

[143] U. Dirnagl, A. Hakim, M. Macleod, M. Fisher, D. Howells, S.M. Alan, G. Steinberg, A. Planas, J. Boltze, S. Savitz, C. Iadecola, S. Meairs, A concerted appeal for international cooperation in preclinical stroke research, Stroke J. Cereb. Circ. 44 (2013) 1754-1760. doi:10.1161/STROKEAHA.113.000734.

[144] P.M.W. Bath, M.R. Macleod, A.R. Green, Emulating multicentre clinical stroke trials: a new paradigm for studying novel interventions in experimental models of stroke, Int. J. Stroke Off. J. Int. Stroke Soc. 4 (2009) 471-479. doi:10.1111/j.1747-4949.2009.00386.x.

[145] U. Dirnagl, M. Fisher, International, multicenter randomized preclinical trials in translational stroke research: it's time to act, J. Cereb. Blood Flow Metab. Off. J. Int. Soc. Cereb. Blood Flow Metab. 32 (2012) 933-935. doi:10.1038/jcbfm.2012.51.

[146] G. Llovera, K. Hofmann, S. Roth, A. Salas-Pérdomo, M. Ferrer-Ferrer, C. Perego, E.R. Zanier, U. Mamrak, A. Rex, H. Party, V. Agin, C. Fauchon, C. Orset, B. Haelewyn, M.-G. De Simoni, U. Dirnagl, U. Grittner, A.M. Planas, N. Plesnila, D. Vivien, A. Liesz, Results of a preclinical randomized controlled multicenter trial (pRCT): Anti-CD49d treatment for acute brain ischemia, Sci. Transl. Med. 7 (2015) 299ra121. doi:10.1126/scitransImed.aaa9853.

[147] S. Maysami, R. Wong, J.M. Pradillo, A. Denes, H. Dhungana, T. Malm, J. Koistinaho, C. Orset, M. Rahman, M. Rubio, M. Schwaninger, D. Vivien, P.M. Bath, N.J. Rothwell, S.M. Allan, A cross- 
laboratory preclinical study on the effectiveness of interleukin-1 receptor antagonist in stroke, J. Cereb. Blood Flow Metab. Off. J. Int. Soc. Cereb. Blood Flow Metab. 36 (2016) 596-605. doi:10.1177/0271678X15606714.

[148] V.E. O'Collins, M.R. Macleod, G.A. Donnan, L.L. Horky, B.H. van der Worp, D.W. Howells, 1,026 experimental treatments in acute stroke, Ann. Neurol. 59 (2006) 467-477. doi:10.1002/ana.20741.

[149] P. Perel, I. Roberts, E. Sena, P. Wheble, C. Briscoe, P. Sandercock, M. Macleod, L.E. Mignini, P. Jayaram, K.S. Khan, Comparison of treatment effects between animal experiments and clinical trials: systematic review, BMJ. 334 (2007) 197. doi:10.1136/bmj.39048.407928.BE.

[150] H.B. van der Worp, D.W. Howells, E.S. Sena, M.J. Porritt, S. Rewell, V. O'Collins, M.R. Macleod, Can animal models of disease reliably inform human studies?, PLoS Med. 7 (2010) e1000245. doi:10.1371/journal.pmed.1000245.

[151] H.B. van der Worp, P. de Haan, E. Morrema, C.J. Kalkman, Methodological quality of animal studies on neuroprotection in focal cerebral ischaemia, J. Neurol. 252 (2005) 1108-1114. doi:10.1007/s00415-005-0802-3.

[152] U. Dirnagl, Bench to bedside: the quest for quality in experimental stroke research, J. Cereb. Blood Flow Metab. Off. J. Int. Soc. Cereb. Blood Flow Metab. 26 (2006) 1465-1478. doi:10.1038/sj.jcbfm.9600298.

[153] M.R. Macleod, H.B. van der Worp, E.S. Sena, D.W. Howells, U. Dirnagl, G.A. Donnan, Evidence for the efficacy of NXY-059 in experimental focal cerebral ischaemia is confounded by study quality, Stroke. 39 (2008) 2824-2829. doi:10.1161/STROKEAHA.108.515957.

[154] J. Ahmed, D.M. Dwyer, T.D. Farr, D.J. Harrison, S.B. Dunnett, R.C. Trueman, Lickometry: A novel and sensitive method for assessing functional deficits in rats after stroke, J. Cereb. Blood Flow Metab. Off. J. Int. Soc. Cereb. Blood Flow Metab. 37 (2017) 755-761. doi:10.1177/0271678X16684141.

[155] J. Boltze, D.-C. Wagner, H. Barthel, M.J. Gounis, Academic-industry Collaborations in Translational Stroke Research, Transl. Stroke Res. 7 (2016) 343-353. doi:10.1007/s12975-016-0475-5.

[156] J. Bernhardt, K. Borschmann, L. Boyd, S. Thomas Carmichael, D. Corbett, S.C. Cramer, T. Hoffmann, G. Kwakkel, S.I. Savitz, G. Saposnik, M. Walker, N. Ward, Moving rehabilitation research forward: Developing consensus statements for rehabilitation and recovery research, Int. J. Stroke Off. J. Int. Stroke Soc. 11 (2016) 454-458. doi:10.1177/1747493016643851.

[157] D. Corbett, S.T. Carmichael, T.H. Murphy, T.A. Jones, M.E. Schwab, J. Jolkkonen, A.N. Clarkson, N. Dancause, T. Weiloch, H. Johansen-Berg, M. Nilsson, L.D. McCullough, M.T. Joy, Enhancing the alignment of the preclinical and clinical stroke recovery research pipeline: Consensus-based core recommendations from the Stroke Recovery and Rehabilitation Roundtable translational working group, Int. J. Stroke Off. J. Int. Stroke Soc. 12 (2017) 462-471. doi:10.1177/1747493017711814. 


\section{Figure legend}

Figure 1. Time window of behavioral testing in relation to brain pathology and regeneration in rats and mice after stroke. For cognitive functions and mood, the number of studies is limited with considerable variations in the outcomes. - - -Sensitive period duration depends on stroke severity. * Depending on the rod type sensitive period increases drastically. 


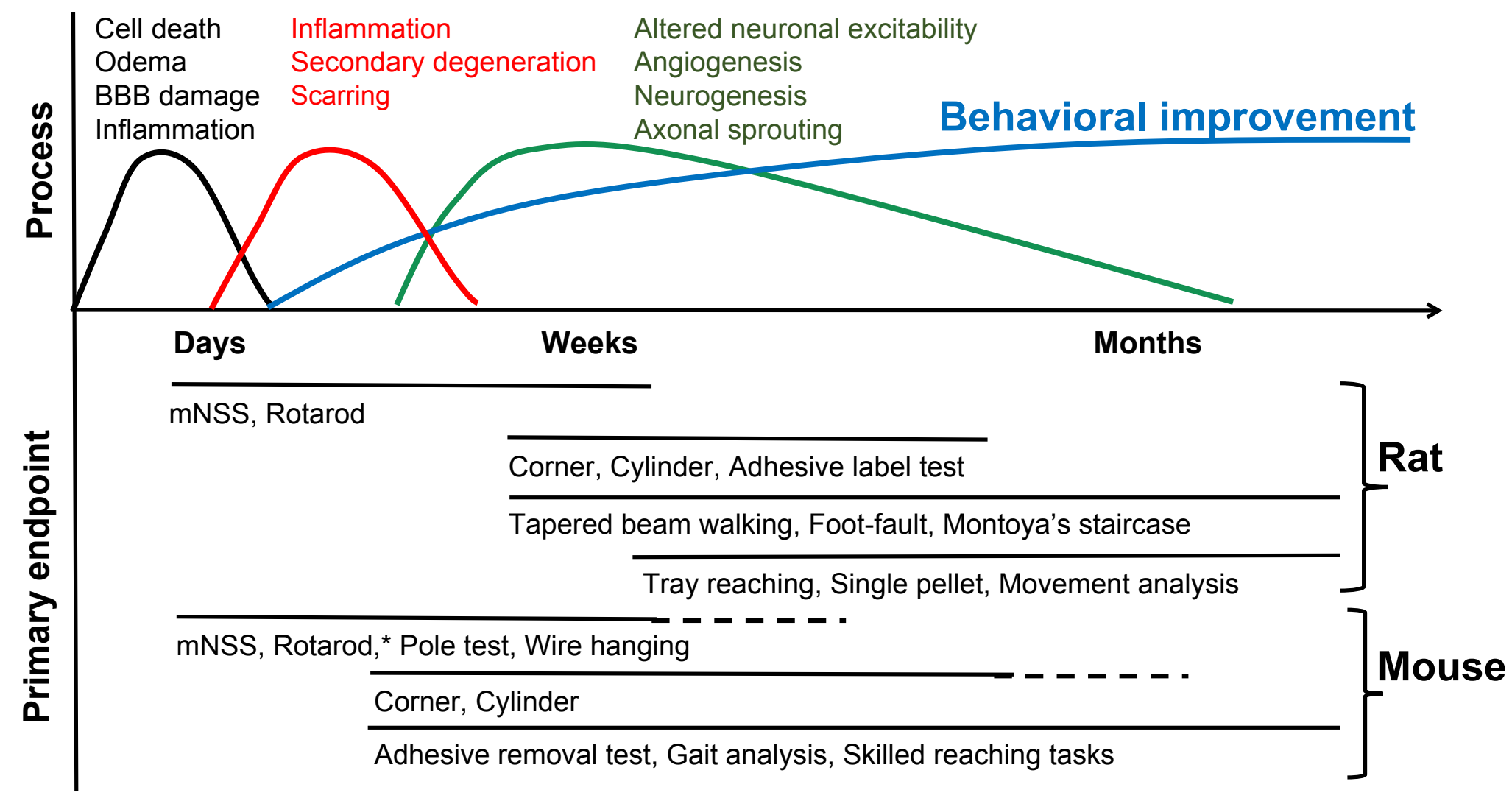


Table 1. Pros and cons of common behavioral tests used in stroke research.

\begin{tabular}{|c|c|c|c|c|}
\hline Behavioral test & Assessment & Time-window & Pros & Cons \\
\hline \multicolumn{5}{|l|}{ Rats } \\
\hline Neurological deficit scores & Sensorimotor functions & $<2$ weeks & Simple; Testing at acute phase & Subjective; Not suitable for long-term evaluation \\
\hline Rotarod & $\begin{array}{l}\text { Coordination, balance and motor } \\
\text { functions }\end{array}$ & $<2$ weeks & Simple; Testing at acute phase & $\begin{array}{l}\text { Compensation; Not sensitive for long-term } \\
\text { evaluation }\end{array}$ \\
\hline Adhesive label & $\begin{array}{l}\text { Forelimb sensorimotor } \\
\text { asymmetry }\end{array}$ & $<4$ weeks & Differentiates between sensory and motor functions, & Removal time affected by motor learning \\
\hline Cylinder test & Spontaneous use of forelimbs & $<4$ weeks & No pretraining; Sensitive to chronic deficits & Habituation \\
\hline Grid walking & $\begin{array}{l}\text { Fore- and hindlimb coordination } \\
\text { and placing }\end{array}$ & $>4$ weeks & No pretraining; Assessment of both fore- and hindlimbs & \\
\hline Montoya's staircase & Forelimb reaching and grasping & $>4$ weeks & Independent use of both forelimbs; Sensitive to lesion size & 2 week pretraining; Food deprivation \\
\hline Single pellet reaching & Skilled forelimb use & $>4$ weeks & Detailed analysis of movements and compensatory strategies & Laborious pretraining \\
\hline Catwalk & Gate & $>4$ weeks & Huge amount of variables and data & Affected by body weight \\
\hline Kinematics & Fine digit control & $>4$ weeks & Differentiation between true recovery and compensation & Laborious \\
\hline Water-maze & Spatial learning and memory & $>4$ weeks & Many references; Variations in test design & Biased with sensorimotor deficit \\
\hline \multicolumn{5}{|l|}{ Mouse } \\
\hline Neurological deficit scores & Sensorimotor functions & $<2$ weeks & Simple; Testing at acute phase & Subjective; Not suitable for long-term evaluation \\
\hline Rotarod & $\begin{array}{l}\text { Coordination, balance and motor } \\
\text { functions }\end{array}$ & $<2.5$ weeks & Simple; Testing at acute phase & $\begin{array}{l}\text { Compensation, not suitable for long-term } \\
\text { evaluation (sensitivity depends on the Rod used) }\end{array}$ \\
\hline Wire hanging & Muscle strength and endurance & $<2$ weeks & Simple; Testing at acute phase & \\
\hline
\end{tabular}




\begin{tabular}{|c|c|c|c|c|}
\hline Pole test & $\begin{array}{l}\text { Motor function and coordination, } \\
\text { bradykinesia }\end{array}$ & $\begin{array}{l}1 \text { week - } 4 \\
\text { week }\end{array}$ & Simple; Testing at acute phase & Anxiety and learning effects performance \\
\hline Adhesive label & $\begin{array}{l}\text { Forelimb sensorimotor } \\
\text { asymmetry }\end{array}$ & $>2$ weeks & $\begin{array}{l}\text { Differentiates between sensory and motor functions; Long } \\
\text { term sensitivity }\end{array}$ & Removal time affected by motor learning \\
\hline Corner Test & $\begin{array}{l}\text { Turning preference and } \\
\text { asymmetry }\end{array}$ & $>2$ weeks & Simple testing; Long term sensitivity & $\begin{array}{l}\text { Repeated testing reduces animals exploratory } \\
\text { behavior; Test becomes gradually more laborious }\end{array}$ \\
\hline Cylinder test & Spontaneous use of forelimbs & $<4-5$ weeks & $\begin{array}{l}\text { No pretraining; Sensitive to chronic deficits depending on } \\
\text { stroke severity }\end{array}$ & $\begin{array}{l}\text { Habituation; Not suitable for repeated testing } \\
\text { with short intervals }\end{array}$ \\
\hline Catwalk & Gait & $>1$ week & Huge amount of variables and data; Long term sensitivity & Affected by body weight and speed variations \\
\hline Skilled reaching tasks & Skilled forelimb use & $>2$ weeks & Detailed analysis of movements and compensatory strategies & Laborious pretraining \\
\hline Kinematics & Fine digit control & $>2$ weeks & Differentiation between true recovery and compensation & Laborious; May require costly equipment \\
\hline Water-maze & Spatial learning and memory & $>2$ weeks & Many references; Variations in test design & $\begin{array}{l}\text { Non-learner mouse; Suboptimal performance in } \\
\text { albino strains; Biased with sensorimotor deficit in } \\
\text { severe strokes }\end{array}$ \\
\hline
\end{tabular}

